\title{
LA NOCIÓN DE ENEMIGO NATURAL EN LA HISTORIOGRAFÍA GRIEGA DEL SIGLO V A.C.*
}

\author{
Paulo Donoso Johnson \\ Pontificia Universidad Católica de Valparaíso. Chile
}

Resumen: Según Heródoto, los verdaderos enemigos por naturaleza son los mismos pueblos griegos que arrastran fuertes disputas históricas ancestrales. Para Tucídides, la enemistad natural está representada en la hostilidad étnica de las colonias sicilianas hacia su metrópolis Atenas. La noción de enemistad natural tiene múltiples significados y usos, pero muy distinta a la que prosperó durante la era helenística.

Palabras claves: enemistad natural - historiografía griega - Heródoto - Tucídides - siglo V a.C.

\section{NOTION OF NATURAL ENEMY IN GREEK HISTORIOGRAPHY ON FIFTH CENTURY B.C.}

Abstract: According to Herodotus, true enemies by nature are the same Greek people who carry strong historic ancestral disputes. For Thucydides, the natural enmity is represented in the ethnic hostility of the Sicilian colonies towards its metropolis Athens. The notion of natural enmity has multiple meanings and uses, but very different from that which flourished during the Hellenistic era.

Keywords: natural enmity - greek historiography - Herodotus - Thucydides Fifht Century B.C.

Recibido: 26.09.2017 - Aceptado: 20.12.2017
Correspondencia: Paulo Donoso Johnson
Email: paulo.donoso@pucv.cl
Doctor en Historia, Università di Pisa.
Profesor Universidad Católica de Valparaíso.
Dirección: Paseo Valle 396, Viña del Mar.

(*) Proyecto DI Iniciación 37/0 2017 VRIEA - PUCV 


\section{Un acercamiento conceptual a la noción de enemigo}

TC a guerra fue uno de los aspectos más importantes que desarrolló la historiografía griega clásica (siglos V - IV a.C) ${ }^{1}$ como hilo conductor en la descripción de la sociabilidad humana en la antigüedad griega. Aristóteles al decir que la guerra existe para que exista la paz ${ }^{2}$ apela a la necesidad intrínseca del ámbito guerrero. Desde el agón homérico entre dioses y hombres hasta la inevitabilidad del conflicto de Tucídides, el análisis historiográfico buscó progresivamente entre la aitíai del enfrentamiento armado los aspectos más recónditos de la naturaleza humana para explicar el origen de la guerra. En este contexto, las partes que se baten en un conflicto son considerados enemigos. Un tipo particular de animadversión es la enemistad natural. Para intentar definir qué significa o cómo se entiende en el mundo griego clásico, es necesario individualizar las definiciones de enemigo a secas.

Para Carl Schmitt, un enemigo no es cualquier competidor ni adversario, tampoco el adversario privado al que se detesta por antipatía sino un conjunto de hombres que, de acuerdo con una posibilidad real, se opone combativamente a otro conjunto análogo. Siguiendo ese criterio sólo es enemigo el enemigo público ${ }^{3}$. El estudio terminológico griego de Chantraine indica que el término $\varepsilon^{\prime} \chi \rho \rho$ ó $\varsigma$ define enemigo bajo un significado de hostilidad y odio ${ }^{4}$. Este uso testimoniado desde la poesía homérica hasta Demóstenes (Hom. Il. III, 416; Hom. Od. IX, 277; Aeschl. Coéf. 309; Pínd. O1. 7, 90; Xen. Ag. VI, 1; Demosth. X, 11) ${ }^{5}$, se puede entender a partir de una fuerte visión dualista de principios que definían el cosmos griego. Uno de ellos, y que define el juego político hacia el siglo $\mathrm{V}$, es el principio

1 El fragmento de Heráclito "La guerra es el padre y el rey de todas las cosas; a unos los muestra como dioses, y a otros como hombres, a unos los hace esclavos y a otros libre" iluminó los textos históricos del mundo antiguo donde pólemos y la discordia ejercen un movimiento vital que ordena al mundo.

2 Aristóteles, Política, VII, 14, 13.

3 Schmitt (2014: 61).

4 David Konstan precisa que $\varepsilon^{\prime} \chi \rho \rho o$ indica una relación de hostilidad recíproca y antagonismo y que en algunos contextos puede connotar el odio. El término que define el odio a secas es $\mu$ íбo $\varsigma$ y ambos son contrarios a la $\varphi \imath \lambda i ́ \alpha$. Peigney (2011: 220).

5 Chantraine (1999). 
platónico "ayuda a tu amigo y daña a tu enemigo", que la literatura griega puso de relieve hasta el siglo IV a.C. ${ }^{6}$. Dentro de una comunidad, el amigo (phíloi) debía ayudar y recibir a otro, de acuerdo a las reglas recíprocas de la kharis. Cuando existía enemistad, o se reemplazaba la amistad a partir de las reglas de reciprocidad negativa o se tomaba venganza de manera directa ${ }^{7}$. Un segundo término utilizado por la lengua griega para definir y representar al enemigo es el de $\delta v \sigma \mu \varepsilon ́ v \varepsilon ı \alpha$, y su significado evoca múltiples usos tales como rencor por cuestiones familiares o económicas, odio político, antipatía instintiva o voluntad homicida ${ }^{8}$. En tercer lugar, $\pi \mathrm{o} \lambda \varepsilon ́ \mu 101$. Este concepto de mucha mayor amplitud y derivado de pólemos acepta las definiciones de la discordia y la enemistad que generalmente nace en el seno íntimo de la familia enfrentando a hermanos y parientes (oikeios pólemos $)^{9}$, pasando por la rivalidad entre ciudades en el contexto de una guerra, hasta llegar a la stasis. Es un concepto utilizado de manera muy selectiva, para relevar o dar énfasis a un tipo particular de enemistad.

El mundo helénico, tal como en nuestros tiempos contemporáneos, entendía que la existencia de enemigos estaba supeditada a un conflicto (pólemos) y bajo esa premisa los antagonistas podían ser diversos y cambiar sus roles según el contexto político y militar. De esta manera los enemigos podían ser internos, externos, políticos, sociales, étnicos, entre otros. Sin embargo, causa inquietud la mención de algunas fuentes de la antigüedad sobre la existencia de enemigos naturales. Plutarco, el biógrafo de Queronea al servicio de Roma, relatando la vida del estratego ateniense Cimón, dice lo siguiente: "[Cimón] Deseaba implicar a los atenienses en una guerra contra los bárbaros y a la vez justamente beneficiarles trayendo a Grecia los recursos de sus enemigos por naturaleza"10.

6 Mitchell-Rhodes (1996:11).

7 Fischer (2002: 209).

8 Ampolo - Fantasia - Porciani (2015: 81). El estudio de Virgilio Costa en el LHG\&L indica que el uso de $\delta v \sigma \mu \varepsilon ́ v \varepsilon ı \alpha$ es poco utilizado por el género historiográfico. Heródoto lo menciona en pocas ocasiones (III, 82, 2 y VII,

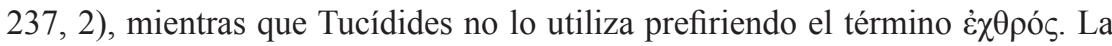
elección de este término provino esencialmente desde la literatura y la tragedia.

9 Loraux (1987).

10 Plutarco, Cimón, 18, 2. 
Es precisamente en el contexto de la Pentekontaetia durante los cincuenta años que separan el fin de las guerras médicas con el comienzo de la guerra del Peloponeso es que el biógrafo nos presenta este episodio. El estratego ateniense dirigió una campaña naval con doscientas trirremes contra Egipto y Chipre en la que buscaba la "disolución de todo el imperio del rey persa"11. En este contexto, Plutarco pone en boca de Cimón un concepto que se ajusta a la visión política del mundo romano y no a la Grecia Clásica $^{12}$. Las palabras de Plutarco aparecen como herederas de una tradición retórica nacida en el seno del mundo clásico, particularmente con Esquilo pero continuada durante la era helenística. En ella se resalta la infamia del medo y el clamor de la venganza, donde Alejandro será el consumador de esa vieja y apasionada aspiración ${ }^{13}$. En este contexto cabe preguntarse qué significa la enemistad natural. La definición de Lynette Mitchell, quien propone que un enemigo natural es una figura filosófica creada con el fin de justificar el miedo correspondido e ideológico ${ }^{14}$ entre griegos y bárbaros es, a nuestro parecer, la más acertada. La autora británica articula su propuesta a partir de los textos clásicos que comenzaron a ser compuestos luego de la victoria griega sobre los persas en las Guerras Médicas. De esta manera, Mitchell cree que el bárbaro como enemigo natural se convirtió en una figura retórica importante, elevándose al nivel de ideología ${ }^{15}$. Este trabajo retórico comienza en las postrimerías del siglo V y se proyecta durante todo el siglo IV a.C. Mitchell concluye que

11 Plutarco, Cimón, 18, 6.

12 Se ha dicho que Plutarco en su evaluación de las grandes batallas de las Guerras Médicas, hace vibrar la cuerda patriótica de sus lectores exaltando batallas o conceptualizando la idea de batallas decisivas en personajes como Cimón. Vs. Gazzano - Traina (2014).

13 García (2009: 47).

14 Mitchell (2007: 39).

15 Mitchell (2007: 335) En su libro Panhellenism and the Barbarian, Lynette Mitchell, dedica en su cuarto capítulo titulado Cultural Contestations, una sección dedicada al bárbaro como enemigo natural. Su argumentación que apela a la utilización del miedo al bárbaro en esta construcción la realiza a partir de la literatura clásica y un particular análisis de cántaros y vasijas en donde los artesanos griegos, diseñaron imágenes decorativas que colaboraron en la construcción del bárbaro como el otro, distinto y extraño al mundo helénico. Vs. Mitchell (2007: 334 - 353). 
Isócrates ${ }^{16}$, Demóstenes ${ }^{17}$ y Platónson los responsables de la explotación del toposdel bárbaro como enemigo natural e implacable de Grecia.

Lo anteriormente expuesto da curso a las interrogantes que se desarrollarán en este artículo. ¿Existieron en la Grecia clásica enemigos naturales? Si así hubiese sido, ¿cómo la historiografía se refiere a este tema y qué criterios determinan a un sujeto o a un conjunto de personas como enemigo natural?

Durante la era clásica, el concepto de enemigo natural si tuvo un espacio entre las distintas tipologías de enemigo y se distingue por su maleabilidad, condicionado por el contexto político en la mayoría de los casos y otras veces producto de la construcción cultural de un imaginario ${ }^{18}$. Demóstenes define al enemigo bajo un criterio acotado, a saber, "no se nace amigo o enemigo, son las acciones las que determinan las dos categorias" 19. Para el orador ateniense, es la ley la que debe castigar en calidad de enemigos quienes realizar acciones de enemigos ${ }^{20}$. Por lo anteriormente dicho y debido a que no se somete a las leyes, el bárbaro podría ser considerado el primer enemigo natural por antonomasia. Su rol de amenaza latente de la civilización ha sido estudiado profundamente desde la tragedia ${ }^{21}$. Sin embargo, se hace necesaria una lectura a partir de la

16 El orador ateniense Isócrates en su Panegírico (IV) y Panatenaico (XII) utiliza abiertamente el concepto de enemistad natural para referirse a los persas. Vs. IsócratesIV, 73; 158 y 184 e Isócrates XII, 102 y 163.

17 Demóstenes en sus discursos sobre la Sinmorías (XIV), por la libertad de los rodios (XV) y contra Midias (XXI), aun cuando no habla explícitamente de enemigos naturales, hace hincapié en el rey persa como enemigo común de Grecia, o en la enemistad auténtica y ancestral. Vs. Demóstenes XIV, 3; Demóstenes XV, 6 y Demóstenes XXI, 48 - 9.

18 Para Hartog, este imaginario está construido a partir de la premisa de LeviStrauss donde la existencia de sociedades calientes y sociedades frías hace que la grecidad se conquiste sobre un fondo de barbarie; siendo los griegos, bárbaros que se convirtieron en griegos, mientras que los bárbaros eran bárbaros y continuaron siéndolo. Hartog $(1999 ; 114)$.

19 Demóstenes, Contra Aristócrates, 56.

20 Idem.

21 Cf. Romilly (1980); Hall (1991); Konstan (1997); Manuel García analiza las formas de representación y alteridad persa en el imaginario griego. La literatura 
historiografía clásica. La poesía homérica revela que durante la Guerra de Troya, aqueos y troyanos no se consideraban enemigos naturales ${ }^{22}$. Aquiles acusa que es llamado a combatir en una guerra propiciada por Agamenón pues "[los troyanos] no son responsables de nada: nunca hasta ahora se han llevado ni mis vacas ni mis caballos, ni nunca en Ftía, de fértiles glebas, nutricia de hombres, han destruido la cosecha"23. En el marco de esta enemistad entre dioses y hombres, el ámbito oriental troyano no se constituye de manera categórica ni como enemigo natural ni siquiera como bárbaro ${ }^{24}$, término usado por Homero sólo una vez para referirse al dialecto de los carios $^{25}$. La historiografía griega clásica, heredera de la épica homérica, intuye la implícita carga histórica y cultural que significó la guerra de Troya como el primer antecedente de enemistad en Occidente. Bajo esta lectura, Heródoto asumiendo su origen en los raptos de mujeres de estirpe de Asia y de Europa, y que los "persas siempre han creido que el pueblo griego era su enemigo",26 establece a través de "la toma de Ilión el origen de su vigente enemistad"27. Si se asume la importante carga semántica de la barbarie, definida por Hartog como un concepto político

clásica griega en general (lírica, logografia jonia, historiografía, tragedia, comedia, filosofía, literatura científica) construyeron su representación de la alteridad persa (señores de la barbarie), a partir de una retórica de la alteridad que se configuró a partir de tres categorías: inversión, diferencia y analogía. Para García esta construcción retórica no fue sino un mecanismo de defensa para cauterizar la angustia sentida frente a un gigantesco enemigo de frontera con vocación imperialista Vs. García (2009: 39 - 53); Jocelyne Peigney presenta una serie de artículos dedicados al problema de la amistad y la enemistad en la Grecia antigua inspirados en el trabajo de David Konstan, Friendship in the Classical World. Estos artículos revisan la dicotomía amigo y enemigo en Homero, Hesíodo, Esquilo, Sófocles, Eurípides, Isócrates y Jenofonte, Vs. Peigney (2011).

22 Galli (2009: 197).

23 Homero, Ilíada I, 153 - 156.

24 Levy (1984: 12).

25 Homero, Ilíada, II, 867.

26 Heródoto, I, 4, 4.

27 Heródoto, I, 4, 5. 
- pues el bárbaro es quien ignora la ciudad y vive sometido a un rey ${ }^{28}$ todos aquellos pueblos, que no viven bajo los términos políticos del mundo griego, deberían ser una amenaza. Sin embargo, el mundo helénico del siglo V a.C. hacía ciertas diferencias respecto a esta categoría.

\section{El enemigo natural en Heródoto}

Heródoto es enfático en señalar que el mundo griego (hellenikón), "posee una identidad racial y lingüística, con una comunidad de santuarios y sacrificios a los dioses, con usos y costumbres similares" 29 . La definición

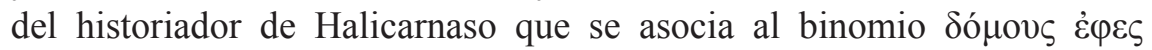
$\tau 10 v \varsigma$ - 'E $\lambda \lambda \alpha ́ \delta$ os $\varphi \theta$ ó $\gamma \gamma o v$ de Esquilo ${ }^{30}$ hace hincapié a una forma de vida según unas condiciones de habitabilidad, disposición del hogar y la unidad idiomática. Esta mirada, muy reiterada por los textos clásicos, reafirma que el ser griego opone por completo la posibilidad de reflejarse con el otro, con el bárbaro. Sin embargo, Anna María Biraschi pone en contexto este punto reproduciendo un interesante testimonio presente en los papiros de Oxirrinco $^{31}$. Se trata de los fragmentos del sofista Antifonte quien define esta dualidad greco-bárbara de la siguiente manera: "Nosotros respetamos $\mathrm{y}$ veneramos a quien es de origen noble, pero a quien tiene origen oscuro, no los respetamos ni los honramos. En esto, nos comportamos unos y otros como bárbaros. De hecho, por naturaleza, bárbaros y griegos somos absolutamente iguales, como comunes al género humano son la actividad de respirar y todos los procesos físicos necesarios para sobrevivir" ${ }^{32}$. Este testimonio proveniente de la sofística pone en evidencia una mirada clásica tardía al problema de la humanidad del bárbaro.

Pero es quizás la tragedia de Esquilo la que resalta de manera más clara la diferencia entre ambos pueblos. Haciendo una lectura detenida de Los Persas - la más histórica de sus tragedias - el dramaturgo presenta a través del sueño de Atosa la siguiente noción:

$28 \operatorname{Hartog}$ (1999: 78).

29 Heródoto, VIII, 144, 2.

30 Esquilo, Siete contra Tebas, 70.

31 P.Oxy XI 1364 = F 44 B Col II.

32 Biraschi (2016: 76). 
"Me pareció ver dos mujeres con rico atuendo: la una, ataviada con vestidos persas, la otra con dóricos, ante mi vista se presentaron, mucho más excelentes en altura que las de ahora e irreprochables por su belleza, y ambas hermanas, del mismo linaje. Como patria habitaban, la una, Grecia, tierra que obtuvo en suerte, la otra la tierra bárbara. Según creía yo ver, ambas andaban preparando cierta discordia entre ellas, y mi hijo, que se enteró, estaba conteniéndolas y apaciguándolas, tras lo cual, las unce a su carro y pone colleras bajo su cuello. Una se ufanabacon este atalaje y tenía su boca obediente a las riendas. La otra, en cambio, se revolvíay con las manos iba rompiendo las guarniciones que al carro la uncían; tras arrancarlas con violencia, quedó sin bridas y partió el yugo por la mitad $[\ldots]^{\prime \prime 33}$.

En esta obra en la que Esquilo atiende al dolor de los vencidos humanizando a los persas, no desde el desprecio sino desde la compasión ${ }^{34}$, el dramaturgo presenta la discordia de ambas mujeres - hermanas

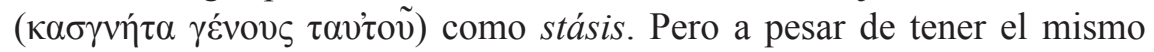
linaje una actúa con violencia y la otra con obediencia. Este quiebre ayuda a entender la creación desde la literatura de un imaginario respecto al enemigo en la Atenas clásica. No es la lengua bárbara, ni la carencia de civilización, ni menos la diferencia de linaje la que hace a al persa enemigo de Grecia. Bien se sabe que la caída del reino de Lidia y la ocupación de Sardes pusieron en jaque la libertad y la autonomía de las colonias griegas en Asia Menor. En este acontecimiento reside el antagonismo y la condición de enemigo que impulsa a los griegos a enfrentarlo en defensa de la libertad. Este reconocimiento no elimina la prolongada y decidida ausencia de un verdadero esfuerzo por comprender la potencia moral de Persia, y continuar siendo bárbaros a ojos de Grecia ${ }^{35}$. Esta visión propia del mundo helénico del siglo $\mathrm{V}$ a.C. interpreta un mundo mediterráneo bipolar, en donde los caracteres principales que definen al bárbaro en la época de las guerras médicas son el despotismo, el servilismo, la crueldad, la barbarie y el exceso ${ }^{36}$. Lo anteriormente dicho ayuda a comprender las motivaciones que Heródoto tuvo al momento de escribir sus Historias,

33 Esquilo, Persas, 180 - 195.

34 Buono-Core (2012: 105).

35 Bengtson (1972: 4).

36 Cardete (2011: 124). 
muy distintas a las de Esquilo. Para Heródoto los únicos aspectos que son inherentes de manera natural a los persas son su fogosidad y su pobreza

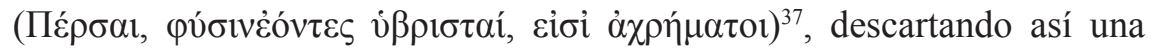
enemistad por naturaleza con el pueblo griego ${ }^{38}$. La mirada esquílea del conflicto medo helénico ${ }^{39}$ alimenta desde el drama ático esta profunda confrontación desde la hermandad y la profanación de la libertad.

Las enemistades que el historiador de Halicarnaso presenta más evidentemente, son aquellas que no son provocadas por cuestiones materiales, sino las antiguas rencillas entre polis griegas aún encendidas, la venganza y el deseo de castigo ${ }^{40}$. Sin utilizar explícitamente la palabra

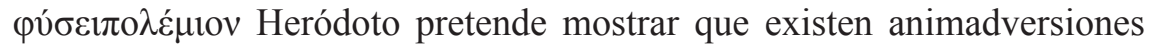
más fuertes y duraderas que la vigente enemistad contra el imperio Aqueménida. De esta manera puede leerse el relato de Heródoto del origen de la enemistad entre atenienses y eginetas luego del robo de estatuas sagradas talladas con olivos provenientes de Ática en el territorio de Epidauro. La isla de Egina, al hacerse más poderosa y al independizarse de Epidauro, saqueó este territorio robando dichas estatuas de madera ateniense, hecho que provocó una campaña de Atenas contra la isla por el sacrílego acto. Heródoto dedica ocho capítulos a este episodio ${ }^{41}$ y subraya de manera precisa y categórica que la enemistad entre Atenas y Egina se produjo por este acontecimiento. Así puede leerse el uso de

37 Heródoto I, 89, 5. Cabe recordar que Heródoto intenta una ecuanimidad en el relato al no decir cómo se llega a la enemistad entre ambos pueblos sino en señalar quién fue el primero en iniciar actos injustos contra los griegos, Heródoto, I, 5, 3. En necesario agregar que dentro de toda su obra, Heródoto reserva un lugar privilegiado a los persas debido a su organización política, el rol de la aristocracia y la división social al interior del Imperio Aqueménida. Vs. Briant (1990) y también Vlassopoulos, K. (2012).

38 En esta misma línea, Domingo Plácido argumenta que las principales diferencias que Heródoto presenta entre griegos y persas, tales como el ultraje de cadáveres, la inferioridad en fuerza y valor y la dependencia de sus jefes en el campo de batalla se explican por motivaciones históricas y no naturales. Vs. Plácido (1986: 22)

39 Hall (1991: 76 - 100); Gallego (2001: 11 - 13).

40 Van Wees (2002: 347).

41 Heródoto, V, $82-89$ 


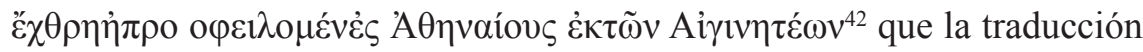
de Biagio Virgilio de 1975, propone como inimicizi aprovata da lungo tempo, haciendo hincapié en la duración del conflicto desde sus inicios hasta el momento en que Heródoto escribe. Esta enemistad, que creemos es por naturaleza, se ve manifestada nuevamente en un relato herodoteo de rencillas entre griegos, en donde el enemigo persa, cumple un interesante rol. Dice Heródoto:

"Inmediatamente después del desastre acaecido en las Termópilas, los tesalios enviaron un heraldo a los focenses, ya que abrigaban hacia ellos un odio inveterado, que se había visto particularmente acrecentados a raíz de su último desastre"43.

El término griego aicìónov se puede traducir también como furia o rabia desde siempre, pero que ha sido traducido como odio inveterado en la traducción castellana de Carlos Schrader. En el contexto de la guerra médica, los focenses eran los únicos habitantes de la Grecia central que no había abrazado la causa meda. Y los tesalios, enemigos naturales de los focenses los instaron a una alianza de acuerdo al siguiente relato de Heródoto:

"Focenses, reconoced de una vez por todas que no podéis compararos con nosotros: hasta ahora, mientras los intereses de la Hélade nos resultaban atractivos, en Grecia hemos sido superiores a vosotros absolutamente siempre; $y$ en estos momentos, tenemos tanta influencia ante el Bárbaro que está a nuestro alcance que os veáis despojados de vuestra tierra y reducidos, incluso, a la condición de esclavos. Todo depende de nosotros, pero, no obstante, no os guardamos rencor; mirad, como desagravio, facilitadnos cincuenta talentos de plata y nos comprometemos a alejar la amenaza que se cierne sobre vuestro país"44.

La posibilidad de los tesalios de dañar a su enemigo de siempre, amenazándoles de volcar la furia del enemigo común de Grecia hacia su territorio es un fenómeno advertido por How y Wells, quienes reafirman este comportamiento en donde el griego generalmente odiaba a un vecino más poderoso que a una potencia extranjera ${ }^{45}$. Este odio entre ciudades

42 Heródoto, V, 82, 1.

43 Heródoto, VIII, 27, 1.

44 Heródoto, VIII, 29.

45 How - Wells (1912: 243). 
es el que mueve el curso de la guerra médica, sumado a la amenaza de la invasión externa que se utiliza como pretexto o como punto de quiebre diplomático.

En relación a la figura del bárbaro, Carlo Galli argumenta que cuando el enemigo es externo, es de alguna manera representable a lo ojos de una sociedad. Esta situación cambia cuando el enemigo es interno. En este contexto se vuelve irrepresentable, es una sombra, un fantasma y en su ambigüedad se hiperrepresenta ${ }^{46}$. Por este motivo ni Homero ni Heródoto ${ }^{47}$ consideran a los pueblos de Asia desde una enemistad natural. Probablemente Aristóteles hereda esta cosmovisión al decir que los [habitantes] de Asia son inteligentes y de espíritu técnico, pero sin coraje por lo que llevan una vida de sometimiento y esclavitud ${ }^{48}$. Motivo por el cual son una amenaza política ${ }^{49}$ en vez de enemigo natural. El retórico ateniense Isócrates propone un punto de vista que podría ser considerado una visión de conjunto del siglo $\mathrm{V}$ a.C. En su discurso Panatenaico, mientras defiende el rol jugado por los lacedemonios en la defensa de la libertad helénica, el orador dice: "Cuando existía entre nosotros un odio común contra los bárbaros y sus reyes, nosotros que estuvimos en muchas guerras, que alguna vez caímos en enormes desgracias, que vimos con frecuencia saqueada y destruida nuestra tierra, nunca confiamos en la amistad ni en la alianza con los bárbaros, sino que, por sus conspiraciones contra los griegos, no dejamos de odiarlos más que a quienes nos hacen

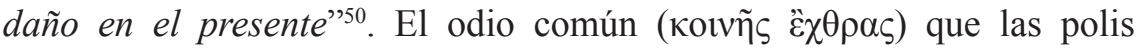
griegas comparten hacia el bárbaro, según Isócrates, no sólo se refleja en consideraciones culturales sino también políticas, donde la ausencia de $\varphi \imath \lambda i ́ \alpha$ se traduce en la imposibilidad de lograr acuerdos o tratados. Las palabras del orador, engrandecen el espíritu de esta férrea enemistad, sin embargo, se debilita ante la realidad histórica, donde la Paz del Rey del

46 Galli (2009: 197).

47 Heródoto no condena al bárbaro ni destaca sus faltas, sino que exalta las cualidades específicas del modo del comportamiento griego, cuya réplica es el bárbaro. Gallego (2001: 2).

48 Aristóteles, Política, VII, 7, 2.

49 En esta misma línea Edith Hall plantea que el bárbaro es visto por los griegos como un "otro hostil" Hall (1991: 62).

50 Isócrates, Panatenaico, 102. 
386 a.C. reúne a espartanos y persas en un humillante tratado favorable para los persas y avalado por Grecia. El odio y la enemistad quedan generalmente retratados como un recurso retórico que no se condice con los procedimientos históricos y políticos.

\section{El uso del concepto en Platón.}

Otra visión del antagonismo entre Asia y Europa, Platón la define a partir de disputa intestina cuando esta es hostilidad familiar y guerra cuando se trata del ajeno y del bárbaro ${ }^{51}$. Esta idea de hostilidad familiar, trabajado por Nicole Loraux, lleva a Platón a relevar el concepto de $\sigma \tau \alpha ́ \sigma ı \varsigma \varsigma$ a partir de la propia vivencia del filósofo durante la última fase de la guerra del Peloponeso, en la que Atenas es gobernada por grupos oligárquicos el $411^{52}$. La persecución política, la guerra de facciones y la conspiración interna marca su visión de guerra entre iguales definiéndola como oíkcíov ¿̋ $\chi \rho \rho \alpha$ (odio familiar). Por otra parte, "el bárbaro que combate contra los griegos y viceversa es una enemistad por naturaleza ( $\pi \mathrm{o} \lambda \varepsilon \mu$ íovs

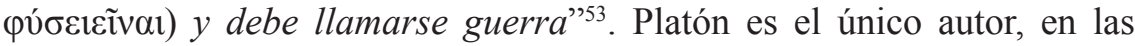
postrimerías del siglo V a.C. que plantea este nuevo paradigma. Griegos y bárbaros son enemigos por naturaleza a la luz de su doctrina y esésta, la noción bélica platónica, la que hereda toda la tradición helenística hasta llegar a Plutarco. El análisis del filósofo deja abierta una interrogante, sólo quienes combaten, ya sea griegos o bárbaros, en un contexto de guerra, pueden ser considerados enemigos naturales.

\section{El enemigo natural en Tucídides}

Una vez concluidas las guerras contra los persas, el mundo griego se verá inmerso en un cambio de era y un cambio de mentalidad. Siguiendo a Popowicz, el enfrentamiento tradicional en batalla, o guerra agonística, donde el objetivo del conflicto era el dominio del territorio, da paso al dominio total de la ciudad y al sometimiento absoluto del enemigo, abatiéndolo, destruyéndolo y aniquilándolo físicamente si fuera posible ${ }^{54}$. La guerra del Peloponeso se presenta como una guerra total que va más

51 Platón, República, V, 470b.

52 Donoso (2014).

53 Platón, República, V, 470c.

54 Popowicz (1995: 235 - 238). 
allá de la guerra defensiva y donde el enemigo se encuentra al interior de la polis y comparte los espacios culturales y convicciones políticas del mundo helénico.

En este contexto aparece una de las pocas menciones a enemigos naturales por parte de un historiador. Durante el armisticio entre las ciudades de Gela y Camarina, durante el octavo año de guerra (424 a.C.) y la primera expedición ateniense en Sicilia, Tucídides nos presenta el discurso de Hermócrates, siracusano hijo de Hermón quien se dirige a la asamblea de delegados de todas las ciudades de la siguiente manera:

"Es preciso, sin embargo, reconocer que, si somos sensatos, esta asamblea no debe ocuparse únicamente de nuestros intereses particulares, sino que debe determinar si todavía podremos salvar a Sicilia entera, amenazada, a mi entender, por las intrigas de los atenienses; hemos de considerar, respecto a la resolución de nuestras diferencias, que los atenienses son unos mediadores mucho más persuasivos que mis palabras, pues, poseyendo el mayor poderío de Grecia, están al acecho de nuestros errores con la presencia de unas pocas naves y, amparándose en el legítimo título de una alianza, con especiosos pretextos, tratan de disponer según su conveniencia lo que es enemistad natural. Porque si emprendemos nosotros la guerra y solicitamos su auxilio, a unos hombres que intervienen aun sin ser llamados, y si a nuestras propias expensas nos causamos perjuicio a nosotros mismos y al mismo tiempo les allanamos el camino del imperio, es natural que, cuando nos vean agotados, vengan entonces con fuerzas más numerosas y traten de poner todo el país bajo su yugo" ${ }^{5}$.

En este párrafo se advierte el uso de la palabra que ha sido traducida como enemistad natural, hostilidad natural y odio innato. El concepto fue analizado por Arnold Gomme en su Comentario Histórico de Tucídides y propone una definición en el contexto de la conferencia de Gela como nuestra propia enemistad mutua ${ }^{56}$, o bien, la enemistad natural entre Atenas y Sicilia en su conjunto ${ }^{57}$. Este aspecto no fue considerado por Simon Hornblower en sus Commentary por lo que suponemos que la propuesta de Gomme cierra el debate acerca de la definición mencionada. Tucídides, consciente de la carga semántica que contiene este tipo de enemistad, eleva

55 Tucídides, IV, 60.

56 Gomme, Vol. I (1962: 514).

57 Gomme, Vol I (1962: 515). 
la potencia retórica de un Hermócrates que busca unir a las polis sicilianas con el verdadero enemigo, Atenas. Usando la clasificación de enemistad de Carlo Galli, este enemigo no puede ser externo pues se trata de Atenas, metrópolis de las principales colonias de la costa oriental de Sicilia. Nicole Loraux cree que Tucídides, para diferenciar $\pi 0 \lambda \varepsilon \mu$ íos, cuyo significado hace referencia tanto al enemigo interior como exterior, habría de definirlo como el faccioso, el enemigo público, en el contexto de un lenguaje de la sedición durante la guerra del Peloponeso ${ }^{58}$.

Siguiendo la lectura del discurso de Hermócrates, el líder siracusano prosigue de la siguiente manera:

"Porque los atenienses no nos atacan por una cuestión de razas, por su hostilidad a una de las dos en que estamos divididos, sino porque codician las riquezas de Sicilia, que poseemos en común" 59 .

Tucídides plantea a través de las palabras de Hermócrates que la estirpe no es el motivo por el cual se genera la enemistad u odio. La

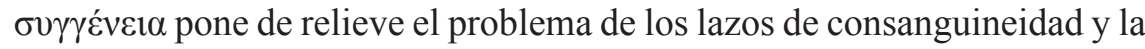
relación política que se genera entre una polis y su ảंoเkía en el contexto de una guerra entre pueblos helénicos. Los asuntos étnicos interesaron sobremanera al historiador ateniense quien dedica el libro VI de su Historia a la arqueología de Sicilia y sus habitantes. Recientes investigaciones ubican al historiador exiliado en Sicilia y no en Tracia, lo que explicaría su detallado conocimiento y exploración del territorio insular sículo ${ }^{60}$. La retórica democrática del siglo $\mathrm{V}$ a.C. pretende demostrar que existió una total planificación de la estrategia ateniense para Sicilia ${ }^{61}$, sin embargo los hechos evidencian que la estrategia de Atenas siempre tuvo un carácter de improvisación ${ }^{62}$ puesto que las fuerzas atenienses nunca previeron los reales alcances de la alianza entre siracusanos y espartanos. Mauro Moggi analizando las peculiaridades de la guerra en Sicilia cree que el carácter interétnico e interhelénico del conflicto entre ciudad metrópolis y

58 Loraux (2008: 109).

59 Tucídides IV, 61, 3.

60 Canfora (2016).

61 Cabe recordar que Tucídides pone en boca de Alcibíades que la conquista de Sicilia se enfocaba en un plan estratégico mayor que era la conquista de Italia. Tucídides, VI, 91, 3.

62 Zahrnt (2012: 640). 
colonia, acentúa los niveles de violencia y conflictividad, en particular, en la destrucción de las polis insulares, una modalidad bélica que según los acuerdos y tratados de la guerra continental, no se debían practicar ${ }^{63}$.

El extenso discurso del orador siciliano se prolonga buscando el consenso entre los pueblos sículos a no negociar con Atenas. Sin embargo, se presenta un aspecto singular en el siguiente párrafo.

"Pretendo, asimismo, que los demás hagáis lo mismo que yo, dando este consentimiento por propio convencimiento y no por imposición del enemigo. Porque no hay ningún deshonor en que los parientes transijan con los parientes, los dorios con los dorios o los calcideos con los de su propia estirpe, y que en general nos sometamos los unos a los otros quienes somos vecinos y habitamos en el mismo país, que además está circundado por el mar, y llevamos el mismo nombre de siciliotas. Nosotros, imagino, haremos nuestras guerras cuando convenga, y de nuevo nos pondremos de acuerdo los unos con los otros mediante negociaciones comunes; pero ante los extranjeros, si somos sensatos, siempre nos defenderemos todos a una; si es cierto que todos corremos peligro cada vez que uno de nosotros sufre daños por separado; y en adelante nunca nos buscaremos fuera del auxilio de aliados y mediadores. Si actuamos de esta manera, en el momento actual no privaremos a Sicilia de un doble beneficio, de verse libre de los atenienses y de la guerra civil, y en el futuro viviremos en ella por nuestra cuenta, en un país libre y menos expuesto a las amenazas de exterior" ${ }^{64}$.

En este párrafo, Hermócrates advierte una práctica habitual en el mundo insular y colonial. El progresivo proceso de independencia de las colonias sicilianas a sus metrópolis, una vez que alcanzaron su propia autonomía económica y militar, hizo que las nuevas polis buscaran sus propias alianzas, por lo general, lejos de su madre patria. En ese contexto,

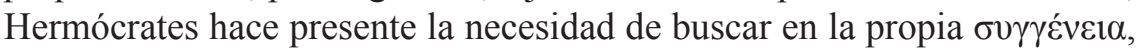
y considerando que más allá de las rivalidades internas, prevale el bien común. En este sentido, el mayor miedo del líder siracusano es que se llegue a considerar de posibilidad de ser amigos de sus peores enemigos

63 Moggi (2006: 67 - 89); Vs. también De Romilly (1985: 207 - 220) donde se presenta un acabado estudio de la guerra entre las ciudades y sus condiciones para la paz.

64 Tucídides, IV, 64, 2 - 5. 


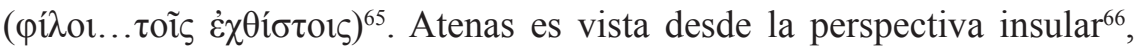
como $\dot{\alpha} \lambda \lambda$ ó $\varphi v \lambda \sigma \varsigma$, un pueblo extranjero, invasor, de otra raza y estirpe.

Finalmente, en el contexto de laembajada ateniense en Camarina, el año 415 a.C., Tucídides en su libro VI, dedicado a la descripción de Sicilia, vuelve sobre el punto de la enemistad natural. El conspicuo orador Hermócrates es quien nuevamente presenta la compleja situación en la que está expuesta la ciudad de Camarina si aceptaba los términos de amistad de la negociación ateniense y sus consecuencias para la isla entera:

"Quizás por cobardía os amoldaréis a las obligaciones que habéis contraído con nosotros y con los invasores y diréis que tenéis una alianza con ellos: alianza que no concertasteis contra vuestros amigos, sino contra vuestros enemigos si alguno os atacaba y para acudir en ayuda de los atenienses cuando alguien les hiciera agravio y no cuando como ahora se lo infieren ellos a los demás, que ni siquiera los reginos, que son calcídeos, quieren ayudar a restaurar en su ciudad a los leontinos, calcídeos también. Sería absurdo que ellos, por sospechas contra el verdadero fin de esa hermosa exigencia del honor, se comportaran con prudencia sin poder justificarlo formalmente, y vosotros en cambio quisierais con un pretexto especioso ayudar a vuestros enemigos naturales y a destruir a quienes con unos lazos más naturales son vuestros hermanos de raza, colaborando con sus enemigos más odiados" ${ }^{67}$.

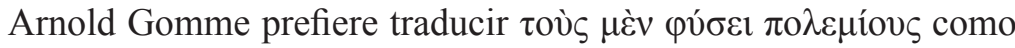
"aquellos que por naturaleza son tus enemigos", haciendo hincapié en que de una relación de enemistad natural se puede abjurar, mientras que nada puede deshacer o cambiar el hecho del parentesco (

65 Tucídides, IV, 63, 2.

66 Por el contrario, la visión y la forma en que la política de Atenas se aproxima a las islas indica desconocimiento y en particular desprecio. Es sabido que los atenienses se referían a Egina como la lagaña del Pireo (Aristóteles, Retórica, 1411a, 15) y el mismo Diálogo de Melos transmitido por Tucídides indican una relación de verticalidad y superioridad con el mundo insular.

67 Tucídides, VI, 79, 1 - 3.

68 Gomme, Vol. IV (1970: 352 - 353). Simon Hornblower analiza detalladamente

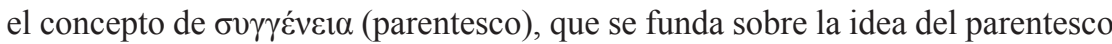
racial de la Antigua Grecia vinculada al mito y la religión. De esta manera, los pueblos que pensaban que estaban conectados por parentesco, rastrearon sus orígenes a los antepasados comunes míticos, o a veces heroicos y eso les llevó a 
El antagonismo racial que presenta Hermócrates ${ }^{69}$, aún sabiendo que su discurso no intenta convertir el conflicto con Atenas en una guerra racial, la realidad política demuestra que las fuerzas en Siracusa están estructuradas para demostrar lo contrario ${ }^{70}$. La oratoria y la figura de Hermócrates, que ha sido motivo de estudios desde hace algún tiempo ${ }^{71}$, constituyen un paradigma. Su permanente argumento era que Atenas era un modelo de estado pérfido en contraposición a Siracusa, su antítesis, que la presenta como una ciudad de intenciones puras y fiel a sus aliados ${ }^{72}$. Dicha cosmovisión, como señala Jacqueline de Romilly, responde a una oposición esencial en todo el pensamiento moral y político de Grecia, desde fines del período arcaico hasta el siglo IV a.C. ${ }^{73}$.

A través de Hermócrates, el historiador Tucídides hace presente el concepto de enemistad natural dentro de la rivalidad siracusanaateniense. Si existió o no esa forma de hostilidad, probablemente no lo sabremos. Sólo sabemos que el historiador utiliza de manera particular y muy acotado un concepto para referirse al conflicto entre pueblos emparentados consanguíneamente. Debido a lo anteriormente dicho, no deja de ser interesante que Tucídides se refiera a la campaña en Sicilia a través de la vibrante arma retórica de la enemistad natural. Estos aspectos demuestran, una vez más, que para Tucídides el verdadero enfrentamiento, que capitaliza el encasillamiento ideológico civilización-barbarie no es el de griegos contra bárbaros, sino el de jonios contra dorios ${ }^{74}$. En segundo

tener cultos en común. Vs. Hornblower, Vol. II (1996: 61 - 80).

69 En consonancia con Eufemo, el enviado de Atenas quien profundiza en el antagonismo al decir que "los jonios siempre han sido enemigos de los dorios" Tucídides, VI, 82, 2.

70 Wilson (1989: 148).

71 En particular el estudio de Marta Sordi que desarrolla su rol de demagogo y pseudo tirano. Vs. Sordi (1981).

72 Farber - Fauber (2001: 47). Los autores incluyen en su artículo un excelente cuadro sinóptico de los orígenes étnicos de las principales ciudades sicilianas y sus alianzas en el contexto de la Guerra del Peloponeso.

73 De Romilly (1980: 741).

74 Cardete (2011: 120). 
lugar, reafirma la noción y la visión del historiador ateniense hacia Esparta ${ }^{75}$ bajo los términos de una profunda admiración.

\section{Conclusiones}

A partir de los ejemplos señalados en los historiadores griegos del siglo V a.C., Heródoto y Tucídides, es posible aproximarnos a una definición del concepto de physei polémion coherente con la visión de mundo de la era clásica. El encuentro bélico entre la Hélade y el imperio persa Aqueménida, generó una serie de nociones acerca del bárbaro en donde predominaron las ideas de un otro desconocido, que representaba todos aquellos anti-valores del mundo griego. Resulta paradigmático que en este contexto, donde el bárbaro era una amenaza para la libertad y la grecidad, no se le representara desde el relato histórico como un enemigo natural.

Los ejemplos expuestos nos permiten proponer que para el mundo griego clásico, la enemistad natural se concebía bajo parámetros muy específicos, a saber: sólo se puede ser enemigo natural en el ámbito público (siguiendo la lectura teórica de Carl Schmitt); el enemigo natural requiere ciertos contextos de animadversión y odio recíproco que no existe entre pueblos de distinta cultura, lengua y costumbre. No se llega a ser enemigo natural siguiendo los conductos legales establecidos tales como la declaración de guerra y el acuerdo de paz. La enemistad natural supera los acuerdos y los pactos debido a que la esencia de este tipo de enemistad reside en la consanguineidad de las partes en conflicto. Son por tanto los enemigos de sangre quienes pueden definirse bajo esta figura, pues compartiendo el mismo origen y estirpe griega, se manifiestan hostiles por conflictos pasados que periódicamente vuelven al presente en contextos y espacios distintos. Nuestro estudio de los textos evidencia que tanto Heródoto como Tucídides coinciden en mostrar la enemistad natural bajo las formas de odio de tiempos remotos, enemistad de estirpe, enemistad por tradición ${ }^{76} \mathrm{y}$ physei polémion de manera explícita como

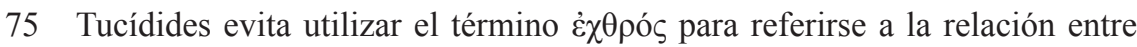
Esparta y Atenas Vs. Ampolo - Fantasia - Porciani (2015: 85).

76 La enemistad tradicional ha sido definida como dos estados que son eterna e inalterablemente hostiles el uno contra el otro, a través de largos siglos. Esta definición ha sido propuesta para analizar la enemistad tradicional entre Esparta y Argos. Kelly (1970).

94 
hemos demostrado en el pasaje tucídideo del discurso de Hermócrates. Este ejercicio intelectual de trasladar al siglo V a.C. un concepto revelado por Plutarco en una de sus Vidas, pero nacido en el seno de la filosofía platónica, sí tiene una posición y un espacio. Sin embargo, el uso dado por Plutarco, donde los enemigos por naturaleza de Cimón de Atenas son los persas, es incongruente al siglo de Pericles. De esta manera es posible concluir que el término physei polémion sí se utiliza en la era clásica y tiene un espacio en las obras históricas de Heródoto y Tucídides. Por el contrario, el significado de enemigos naturales asociado a la enemistad entre griegos y bárbaros no le pertenece al tiempo de los Padres de la Historiasino a la historiografía alto imperial del siglo II d.C., heredera de la cultura helenística, a la que pertenece el biógrafo de Queronea.

\section{Referencias Bibliográficas}

\section{Fuentes}

ARISTÓTELES (1989): Política, Madrid: Gredos. Trad. Manuela García. ESQUILO (1982): Tragedias, Madrid: Gredos. Trad. Bernardo Perea.

HERÓDOTO (1989): Historia, Libro VIII. Madrid: Gredos. Trad. Carlos Schrader.

HERÓDOTO (1960): Historias, Libro I, Barcelona: Ediciones Alma Mater. Trad. Jaime Berenguer.

HOMERO (1982): Ilíada, Madrid: Gredos. Trad. Emilio Crespo.

ISÓCRATES (1980): Discursos, Madrid: Gredos, Trad. Juan Manuel Guzmán.

PLATÓN(1988): Discursos, República, Vol. IV, Madrid: Gredos, Trad. Conrado Eggers.

SCHMITT, C. $\left(2014^{2}\right)$ : El concepto de lo político. Texto de 1932 con un prólogo y tres corolarios, Trad. Rafael Agapito, Madrid: Alianza Editorial.

TUCIDIDE (2011): La guerra del Peloponneso, Milano: BUR. Trad. Franco Ferrari.

TUCÍDIDES (2002): Historia de la guerra del Peloponeso, Madrid: Centro de Estudios Políticos y Constitucionales. Trad. Francisco Rodríguez Adrados.

\section{Referencias bibliográficas}

AMPOLO, C. - FANTASIA, U. - PORCIANI. L (2015): Lexicon Historiographicum Graecum et Latinum, Vol. 3, Pisa: Edizioni della Normale. 
BIRASCHI, A. M. (2016): "Greci e barbari in Tucidide", Quaderni di Storia XLII, 84, $59-82$.

BRIANT, P. (1990): "Hérodote et la société perse" en REVERDIN, O. - GRANGE, B. (1990) Hérodote et les peuples non grecs, Genève: Fondation Hardt.

BUONO-CORE, R. (2012): El Mediterráneo y la Diplomacia en la Antigua Grecia, Valparaíso: Ediciones Universitarias de Valparaíso.

CANFORA, L. (2016): Tucidide. La menzogna, la colpa, l'esilio, Bari: Gius. Laterza \& Figli Editori.

CARDETE DEL OLMO, M. (2011): "El valor de la propaganda en la construcción del enemigo: Atenas y las guerras médicas" en CORTÉS COPETE, J.M. - MUÑIZ, E. - GORDILLO, R. (2011) Grecia ante los Imperios. $V$ Reunión de historiadores del mundo griego, Sevilla: Secretariado de Publicaciones Universidad de Sevilla, 119 - 130

CHANTRAINE, P. (1999): Dictionnaire etymologique de la langue grecque: histoire des mots. París: Klincksieck.

DE ROMILLY, J. (1985): “Guerre et paix entre cités” en VERNANT, J.P (1985) Problèmes de la guerre en Grèce ancienne, Paris: Éditions de l'École des Hautes Études en Sciences Sociales, 207- 220.

DE ROMILLY, J. (1980): “Amis et ennemisau Ve siècleavant J.C.” en $\Phi i \lambda i ́ a \varsigma$

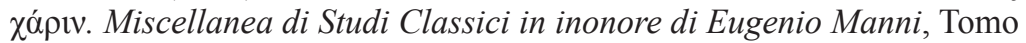
III, Roma: Giorgio Bretschneider, 739 - 746

DONOSO, P. (2014): "El léxico oligárquico en el libro VIII de Tucídides" Byzantion Nea Hellás 33, $47-65$.

FARBER, C.M. - FAUBER, C.M. (2001): "Hermocrates and Thucydides: Rhetoric, Policy, and the Speeches in Thucydides' History", Illinois Classical Studies 26, 37 - 51

FISCHER, N. (2002): "Popular Morality in Herodotus" en BAKKER, E.J.- DE JONG, I. - VAN WEES, H. (2002) Brill's Companion to Herodotus, Leiden: Brill, 199 - 224.

GALLEGO, J. (2001): "En los márgenes de la igualdad: figuras del bárbaro en la Atenas democrática"en LÓPEZ BARJA, P. - REBOREDA MORILLO, S. (2001) Fronteras e identidad en el mundo griego antiguo, Santiago de Compostela: Imprenta Universitaria, 157 - 179.

GALLI, C. - MINERVINI, A. - SITZE, A. (2009): "On War and on the Enemy" CR: The New Centennial Review 9, 2, 195 - 219.

GARCÍA, M. (2009): El Gran Rey de Persia: Formas de representación de la alteridad persa en el imaginario griego, Instrumenta 33, Barcelona: Universitat de Barcelona.

GAZZANO, F. - TRAINA, G. (2014): "Plutarque, historien militaire?", Ktèma. Civilisations de l'Oriente, de la Grèce et de Rome antiques 39, 347 - 370.

GOMME, A. W. - ANDREWES, A. - DOVER, K.J.(1962, 1970): A Historical Commentary on Thucydides, Vols. I y IV, Oxford: Clarendon Press. 
HALL, E. (1991): Inventing the Barbarian. Greek Self-Definition through Tragedy, Oxford: Clarendon Press.

HARTOG, F. (1999): Memoria de Ulises. Relatos sobre la frontera en la antigua Grecia, Buenos Aires: Fondo de Cultura Económica.

HORNBLOWER, S. (2004², 1996): A Commentary on Thucydides, Vols. I y II, Oxford: Clarendon Press.

KELLY, T. (1970): "The Traditional Enmity between Sparta and Argos: The Birth and Development of a Myth" The American Historical Review 75, 4, 971 $-1003$.

KONSTAN, D. (1997): Friendship in the Classical World, New York: Cambridge University Press.

LEVY, E. (1984): "Naissance du concept de barbare" Ktèma. Civilisations de l'Oriente, de la Grèce et de Rome antiques 9, 5-14.

LORAUX, N. (2008): La guerra civil en Atenas. La política entre la sombra y la utopía, Madrid: Akal.

LORAUX, N. (1987): "Oikeios polemos: la guerra nella famiglia", Studi Storici $28,1,5-35$.

MITCHELL, L. (2007): Panhellenism and the Barbarian in Archaic and Classical Greece, United Kingdom: The Classical Press of Wales.

MITCHELL, L.G. - RHODES, P.J. (1996): "Friends and Enemies in Athenian Politics" Greece \& Rome 43, 1, 11 - 30.

MOGGI, M. (2006): "Particularità della guerra in Sicilia?" en VAGGIOLI, M. (2006) Guerra e pace in Sicilia e nel Mediterraneo antico (VIII - III sec. a.C.), Vol. I, Pisa: Edizioni della Normale, 67 - 89.

PEIGNEY, J. (2011): Amis et ennemis en Grèce ancienne, Bordeaux: Editions Ausonius.

PLÁCIDO, D. (2012): "Las relaciones de amistad en la ciudad griega, entre arcaísmo y helenismo" Revista digital de la Escuela de Historia 6, 35 $-46$.

PLÁCIDO, D. (1986): "De Heródoto a Tucídides" Gerión. Revista de Historia Antigua 4, 17 - 46.

POPOWICZ, E. (1995): “La guerra total en la Grecia clásica (431 - 338)”, Polis. Revista de ideas y formas políticas de la antigüedad clásica 7, 219-245.

SORDI, M. (1981): "Ermocrate di Siracusa: Demagogo e tiranno mancato" in GASPERINI, L. (1981) Scritti sul mondo antico in memoria di Fulvio Grosso, Roma: Giorgio Bretschneider, 595 - 600.

VAN WEES, H. (2002): "Herodotus and the Past", en BAKKER, E.J.- DE JONG, I. - VAN WEES, H. (2002) Brill's Companion to Herodotus, Leiden: Brill, 321- 349.

VERNANT, J.P. (1985): Problèmes de la guerre en Grèce ancienne, Paris: Éditions de l'École des Hautes Études en Sciences Sociales.

VIRGILIO, B. (1975): Commento storico al quinto libro delle "Storie" di Erodoto, Pisa: Giardini Editori e Stampatori in Pisa. 
PAULO DONOSO J.: La noción de enemigo natural en la historiografía griega...

VLASSOPOULOS, K. (2012): "The barbarian repertoire in Greek culture" en

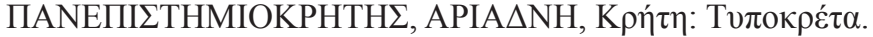

WILSON, J.R (1989): "Shifting and Permanent 'Philia' in Thucydides", Greece \& Rome 36, 2, 147 - 151.

ZAHRNT, M. (2012): "Sicily and Southern Italy in Thucydides", en RANGAKOS, A. - TSAKMAKIS, A. (2012) Brill's Companion to Thucydides, Leiden: Brill, $629-655$. 